\title{
Can CQ Be Completely Replaced by Alternative Initiators in Dental Adhesives?
}

\author{
Nicoleta ILIE and Reinhard HICKEL \\ Dental School of the Ludwig-Maximilians-University, Goethestr. 70, 80336 Munich, Germany \\ Corresponding author, Nicoleta ILIE; E-mail: nicoleta.ilie@dent.med.uni-muenchen.de
}

Received August 15, 2007/Accepted October 9, 2007

Despite good clinical acceptance, photoinitiating systems based on camphorquinone and amines raise concerns in terms of yellowing, aging, toxicity, or degradation in low $\mathrm{pH}$ conditions. This study aimed to prove whether CQ could be successfully replaced by alternative initiators in adhesive systems. Further, the efficiency of a prototype dual-wavelength LED (=Light Emitting Diode) curing unit was analyzed.

In two commercial adhesive systems, CQ was completely replaced by Lucirin TPO. The commercial adhesives and their experimental counterparts were evaluated after curing for 10 seconds and 20 second with two dual-wavelength LED units and one regular LED unit, by applying the curing unit on the adhesive surface at two distances of $0 \mathrm{~mm}$ and $5 \mathrm{~mm}$. Degree of cure and mechanical properties (Vickers hardness and modulus of elasticity) were assessed after 24-hour storage in distilled water at $37^{\circ} \mathrm{C}$.

Experimental data showed that the CQ-amine system could be completely replaced by Lucirin TPO when dual-wavelength LED unit was used for photoactivation.

Keywords: Adhesives, Degree of cure, Mechanical properties

\section{INTRODUCTION}

Photoinitiating systems based on camphorquinone (CQ) are the widely and most successfully used visible-light photoinitiators in dental restorative resins $^{1,2)}$. Although $\mathrm{CQ}$ is able to start the photopolymerization process by itself, the process will occur at a low rate ${ }^{1)}$. To speed up this reaction, coinitiators or accelerators are needed. The most frequently used accelerators for dental materials are aromatic amine (ethyl 4-dimethylaminobenzoate (EDMAB)), aliphatic amine (2-(dimethylamino)ethyl methacrylate (DMAEMA)), or piperidine (1,2,2,6,6-pentamethylpiperidine $)^{1,2}$. In general, tertiary amines are highly effective hydrogen donors. On a further note, tertiary aromatic amines with a para electron-donating substituent can generate more radicals effectively than tertiary aliphatic amines with an electron-withdrawing substituent ${ }^{3}$.

Despite their good clinical acceptance, photoinitiating systems based on camphorquinone and amines present some drawbacks. Although used in very small amounts (ppm), the yellow-colored camphorquinone significantly influences the composite color ${ }^{4}$. As for amines, they are known to form byproducts during photoreaction, which also tend to cause yellow to red/brown discolorations under the influence of light or heat ${ }^{5)}$. Apart from the aesthetical aspect, biocompatibility - and conversely toxicity and mutagenicity - are also the concerns and reservations connected with the use of amines compounds for dental applications ${ }^{6-8)}$.

Another area of concern stems from the potential degradation of the initiation system in aggressive conditions such as the low $\mathrm{pH}$ of self-etching enamel- dentin adhesives. By the acid-base reaction between the acidic monomers of self-etching adhesives and the amine coinitiators of the initiator system, the concentration of amine and thus that of the formed amine radical - which is responsible for the initiation of polymerization - will be reduced. These decreases will result in retarded or insufficient polymerization ${ }^{9-11}$.

To overcome problems associated with yellowing, aging, toxicity, or incompatibility by the use of simple aromatic or aliphatic amines in conjunction with CQ, some polymeric or macromolecular photoinitiators like aromatic tert-amine with a bisphenolA skeleton have been recommended ${ }^{12)}$. In the same vein, the initiator $\mathrm{CQ}$ can be replaced by polymeric radical photoinitiators bearing the photosensitive $\mathrm{CQ}$ groups in the side chain ${ }^{13)}$.

Another promising way to overcome the use of amines as accelerators is found in Norrish Type I photoinitiator systems ${ }^{14}$. They are based on photochemical cleavage of aldehydes and ketones into two free radical intermediates, which initiate polymerization without the need for an additional amine. Recent developments of Norrish Type I photoinitiator systems for dental materials include acyl phosphonates, acylphosphine oxides, bisacylphosphine oxides, and titanocenes ${ }^{14)}$. However, only acylphosphine oxides, such as Lucirin TPO (2,4,6-trimethylbenzoyldiphenylphosphine oxide), are used in commercially available products ${ }^{11}$.

The effective wavelength range for activating camphorquinone has been reported to be between 400 and $500 \mathrm{~nm}$, with a maximum excitation wavelength at $c a .470 \mathrm{~nm}^{15)}$. Consequently, this initiator is perfectly adapted to the emission spectra of all curing unit types. In comparison, the absorption of 
Lucirin TPO lies at the long-wave end of ultraviolet range $(340-430 \mathrm{~nm})$ with a peak absorption at 390 $\mathrm{nm}$ (measured in toluene ${ }^{16)}$ ). The use of this initiator is hence not compatible with most of the new dental Light Emitting Diode (=LED) polymerization units, which emit light in the wavelength range of 450 to $500 \mathrm{~nm}$. In order not to forfeit the advantages of LED units, several manufacturers have developed dual-wavelength LED units by combining LEDs with two different wavelengths. A primary LED provides curing for products containing camphorquinone (peak at $c a .470 \mathrm{~nm}$ ) and accessory LED light sources (peak at $c a .400 \mathrm{~nm}$ ) provide curing for alternative initiators.

The purpose of this in vitro study was to evaluate whether $\mathrm{CQ}$ could be successfully replaced by Lucirin TPO in adhesive systems, by assessing their degree of cure and mechanical properties. Further, the efficiency of a prototype dual-wavelength LED curing unit was compared against a commercial dual-wavelength LED and a conventional LED. Four null hypotheses were tested: (1) Lucirin TPO is able to replace $\mathrm{CQ}$ without diminishing the properties of adhesive; (2) the prototype curing unit improves the adhesive's characteristics in comparison to the commercial curing units; (3) increasing the polymerization time from 10 seconds to 20 seconds will improve the measured characteristics; and (4) an increased distance between curing unit and adhesive surface will worsen the properties of adhesive.

\section{MATERIALS AND METHODS}

\section{Dental adhesive materials}

Four bonding materials were selected in this study for the evaluation of degree of cure and mechanical properties (Table 1). Two of which were commercially available and photoinitiated by a CQ-amine system: a light-curing, filled, single-component adhesive used in conjunction with total etch technique (Excite) and a light-curing, unfilled, single-compo- nent bonding material (Heliobond). The other two were experimental materials with the same chemical compositions, but with Lucirin TPO as initiator.

\section{Photopolymerization of dental adhesives}

For the curing units, the following were used in this study:

- Prototype, a dual-wavelength LED unit (Ivoclar Vivadent, Schaan, Lichtenstein, Serial No. PT7, Low Power Mode);

- UltraLume 5, a dual-wavelength LED unit (Ultradent, South Jordan, USA, Serial No. 503148, Standard curing lens); and

- BluePhase, a conventional LED unit (Ivoclar Vivadent, Schaan, Lichtenstein, Serial No. 1629243, Low Power Mode)

For curing time, the bonding materials were cured for 10 seconds and 20 seconds. For distance between the curing unit and adhesive surface, they were set at $0 \mathrm{~mm}$ and $5 \mathrm{~mm}$.

Spectral distributions and irradiances of the tested curing units were determined by means of a calibrated fiber optic spectrometer equipped with an integrating sphere (X4 Light Analyzer, GigahertzOptik, Puchheim, Germany). Total irradiance was obtained by integral calculus of irradiance as a function of wavelength over the entire wavelength range, and then divided by the effective area of the curing unit tip. Tip diameter was measured with a digital micrometer, whereby effective area was defined as the area of the tip without cladding.

\section{Evaluation of degree of cure}

To determine the degree of cure, thin adhesive films were measured with an FTIR spectrometer equipped with an attenuated total reflectance (ATR) accessory (Nexus, Thermo Nicolet, Madison, USA). Since thin films tend to flutter and lose plan-parallelism during storage in water, small plastic sample holders were manufactured (Plexiglas; $2 \mathrm{~mm}$ thickness, $6 \mathrm{~mm}$ length, $6 \mathrm{~mm}$ width). To ensure adhesion of adhesive

Table 1 Materials and their corresponding manufacturers and chemical compositions

\begin{tabular}{|c|c|c|c|c|}
\hline Material & Manufacturer & LOT & Chemical composition & Initiator \\
\hline Heliobond & Ivoclar-Vivadent & K00250 & 60\% Bis-GMA & $\mathrm{CQ}$ \\
\hline Heliobond experimental & Ivoclar Vivadent & RYH004 & $\begin{array}{l}\text { 40\% Triethylene } \\
\text { glycoldimethacrylate }\end{array}$ & Lucirin-TPO \\
\hline Excite & Ivoclar Vivadent & K01754 & $\begin{array}{l}\text { 11\% Phosphonic acid acrylate } \\
\text { 15\% HEMA } \\
53 \% \text { Dimethacrylates }\end{array}$ & $\mathrm{CQ}$ \\
\hline Excite experimental & $\begin{array}{l}\text { Ivoclar } \\
\text { Vivadent }\end{array}$ & R38-043-1 & $\begin{array}{l}20 \% \text { Alcohol } \\
0.5 \% \mathrm{SiO}_{2}\end{array}$ & Lucirin-TPO \\
\hline
\end{tabular}


film on the substrate, the Plexiglas samples were additionally sandblasted. The adhesive was then applied on the sample holder, covered with a thin Mylar foil, and polymerized according to the light curing conditions described above.

Degree of cure $(n=6)$ was measured once for the uncured materials to determine the initial conditions, as well as at 24 hours after polymerization and storage in distilled water at $37^{\circ} \mathrm{C}$. Diameter of the measured surface was $800 \mu \mathrm{m}$. Wavenumber range of the spectrum was $4000-650 \mathrm{~cm}^{-1}$, and FTIR spectra were recorded with four scans at a resolution of $4 \mathrm{~cm}^{-1}$. Each FTIR measurement was collected as an average value of 50 spectra.

To determine the percentage of the remaining unreacted double bonds, the degree of cure (=DC) was assessed with two methods. First, variation in the peak height ratio of the absorbance intensities of methacrylate carbon double bond (peak at 1634 $\mathrm{cm}^{-1}$ ) and internal standard (aromatic carbon double bond, peak at $1608 \mathrm{~cm}^{-1}$ ) before and after curing was assessed as follows:

$\mathrm{DC}_{\text {Height }} \%=\left[1-\frac{\left(1634 \mathrm{~cm}^{-1} / 1608 \mathrm{~cm}^{-1}\right)_{\text {Peak height after curing }}}{\left(1634 \mathrm{~cm}^{-1} / 1608 \mathrm{~cm}^{-1}\right)_{\text {Peak height before curing }}} x 100\right]$

Next, variation in the peak area ratio of the same functional groups was evaluated (Fig. 1):

$\mathrm{DC}_{\text {Area }} \%=\left[1-\frac{\left(1634 \mathrm{~cm}^{-1} / 1608 \mathrm{~cm}^{-1}\right)_{\text {Peak area after curing }}}{\left(1634 \mathrm{~cm}^{-1} / 1608 \mathrm{~cm}^{-1}\right)_{\text {Peak area before curing }}} x 100\right]$

\section{Evaluation of mechanical properties}

To correlate the degree of cure with the mechanical properties, hardness and modulus of elasticity were evaluated after 24-hour water storage using an automatic microhardness indenter (Fischerscope H100C, Fischer, Germany). Test procedure was carried out with feedback-controlled force actuator. The test load increased and decreased with constant speed between $0.4 \mathrm{mN}$ and $30 \mathrm{mN}$. During the load-unload hysteresis, the load and penetration depth of the indenter were continuously measured. Universal hardness is defined as the test force divided by the apparent area of the indentation under the applied test force. From a multiplicity of measurements stored in a database supplied by the manufacturer, a conversion factor between Universal hardness and Vickers hardness was calculated and input into the software, so that the measurement results were indicated in the more familiar Vickers hardness units.

As for the elastic indentation modulus, it was calculated from the slope of the tangent of indentation depth curve at maximum force.

\section{Statistical analysis}

Results were compared using one- and multiple-way ANOVA (general linear model) and Tukey's HSD post hoc test ( $\alpha=0.05$ ), as well as Pearson's correlation analysis (SPSS 14.0).

In the multivariate analysis, the following null hypotheses were tested:

1. Lucirin TPO is able to replace CQ without diminishing the properties of adhesive.

2. The prototype LED performs better than BluePhase and UltraLume 5.

3. An increase in polymerization time from 10 seconds to 20 seconds will improve the measured characteristics.

4. An increase in distance between curing unit and sample surface from direct contact to 5 $\mathrm{mm}$ apart will diminish the measured characteristics.

\section{RESULTS}

\section{Characteristics of tested curing units}

Figure 1 shows the spectral distributions of the tested curing units. The tested prototype was a dualwavelength LED unit with peak wavelengths at 370 $\mathrm{nm}$ and $530 \mathrm{~nm}$. The unit was tested in Low Power Mode indicated for curing adhesives (irradiance = $650 \mathrm{~mW} / \mathrm{cm}^{2}$ ). A first peak was measured at $405 \mathrm{~nm}$ and a second one, matching the absorption of camphorquinone, at $463.3 \mathrm{~nm}$.

UltraLume 5 is also a dual-wavelength LED unit with a wavelength range of $370-520 \mathrm{~nm}$ and a total irradiance of $735 \mathrm{~mW} / \mathrm{cm}^{2}$. The curing unit comprised five light-emitting diodes and a large, oval $(11 \times 7.5 \mathrm{~mm})$ curing footprint. A stronger peak at $458 \mathrm{~nm}$ was produced by a LED situated in the center. Four accessory LEDs generated a peak at lower wavelength $(400 \mathrm{~nm})$.

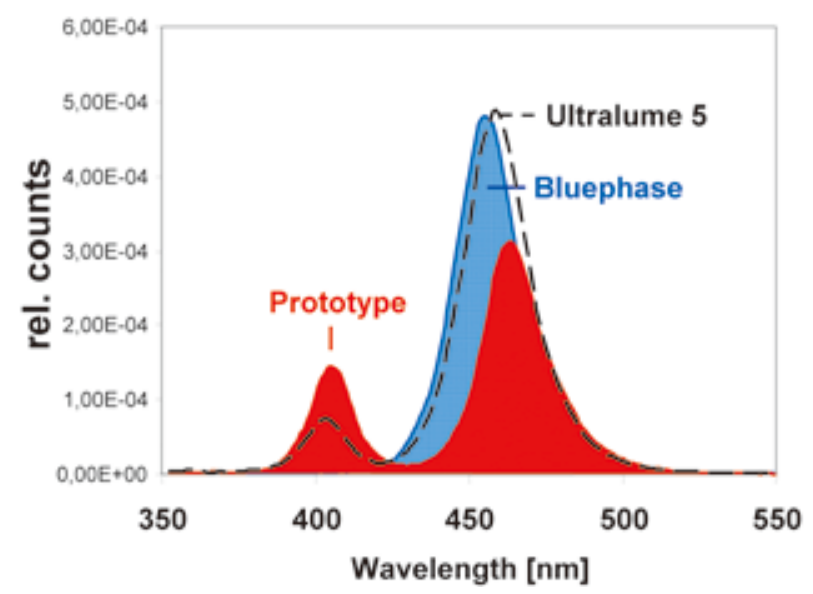

Fig. 1 Spectral distributions of the tested curing units. 
The regular LED unit, BluePhase, was tested in Low Power Mode. It gave an irradiance of $650 \mathrm{~mW} /$ $\mathrm{cm}^{2}$ with a single peak at $456.0 \mathrm{~nm}$ and a wavelength range of $410-520 \mathrm{~nm}$.
Mechanical properties and degree of cure

Tables $2 \mathrm{a}$ and $2 \mathrm{~b}$ summarize the measured mechanical properties and degree of cure, as well as the statistical analysis results (one-way ANOVA and Tukey' HSD post hoc test), of the tested dental adhe-

Table 2 Adhesives, curing conditions, and measured mechanical properties ( $\mathrm{E}=$ modulus of elasticity, HV=Vickers hardness; $n=6$ ) and degree of cure (evaluated by measuring the peak height and peak area; $n=6$ ). Superscript letters indicate statistically homogeneous subgroups (Tukey's HSD test, $\alpha=0.05$ ). B=BluePhase, Low Power Mode; U=UltralLume 5; P=Prototype, Low Power Mode. (a) Excite and Exite-experimental; (b) Heliobond and Heliobond-experimental

a) Excite and Excite- experimental:

\begin{tabular}{|c|c|c|c|c|c|}
\hline Adhesive & Exposure & $\mathrm{E}$ & $\mathrm{HV}$ & DC-Height & DC-Area \\
\hline Excite & P-10s & $4.0^{\mathrm{bcd}}(0.2)$ & $24.3^{\mathrm{e}}(1.5)$ & $87.0^{\mathrm{ef}}(0.9)$ & $90.8^{\mathrm{ef}}(0.6)$ \\
\hline Excite & $\mathrm{P}-20 \mathrm{~s}$ & $4.2^{\mathrm{fg}}(0.1)$ & $24.3^{\mathrm{e}}(1.1)$ & $86.6^{\mathrm{ef}}(0.7)$ & $90.9^{\mathrm{ef}}(0.5)$ \\
\hline Excite & B-10s & $4.1^{\text {cdefg }}(0.1)$ & $21.9^{\text {cd }}(1.5)$ & $71.8^{\mathrm{ab}}(12.4)$ & $78.0^{\mathrm{ab}}(11.4)$ \\
\hline Excite & B-20s & $4.1^{\text {bcdef }}(0.3)$ & $23.2^{\text {cde }}(1.8)$ & $72.1^{\mathrm{abc}}(9.4)$ & $78.2^{\mathrm{bc}}(9.1)$ \\
\hline Excite & $\mathrm{U}-10 \mathrm{~s}$ & $4.1^{\text {bcdef }}(0.3)$ & $22.6^{\mathrm{cd}}(1.7)$ & $85.4^{\mathrm{ef}}(2.6)$ & $89.9^{\mathrm{ef}}(2.8)$ \\
\hline Excite & $\mathrm{U}-20 \mathrm{~s}$ & $4.2^{\mathrm{fg}}(0.1)$ & $24.5^{\mathrm{e}}(1.5)$ & $90.1^{\mathrm{ef}}(1.0)$ & $93.6^{\mathrm{f}}(0.7)$ \\
\hline Excite & P-10s-5mm & $4.0^{\mathrm{bcd}}(0.1)$ & $19.8^{\mathrm{b}}(1.4)$ & $80.7^{\mathrm{de}}(2.8)$ & $84.5^{\text {bcde }}(2.5)$ \\
\hline Excite & P-20s-5mm & $4.0^{\mathrm{bcd}}(0.1)$ & $21.8^{\mathrm{c}}(1.9)$ & $85.0^{\mathrm{ef}}(1.3)$ & $87.5^{\mathrm{ef}}(1.0)$ \\
\hline Excite & B10s-5mm & $3.3^{\mathrm{a}}(0.8)$ & $17.7^{\mathrm{a}}(3.7)$ & $66.6^{\mathrm{a}}(2.5)$ & $70.0^{\mathrm{a}}(2.6)$ \\
\hline Excite & B20s-5mm & $4.0^{\mathrm{bcd}}(0.3)$ & $22.2^{\text {cd }}(0.8)$ & $76.0^{\text {bcd }}(1.9)$ & $79.4^{\mathrm{bcd}}(1.8)$ \\
\hline Excite & U10s-5mm & $3.9^{b}(0.2)$ & $21.8^{\mathrm{c}}(1.2)$ & $83.1^{\mathrm{def}}(1.1)$ & $86.1^{\text {cdef }}(1.3)$ \\
\hline Excite & U20s-5mm & $4.0^{\text {bcde }}(0.1)$ & $22.0^{\text {cd }}(1.6)$ & $85.1^{\mathrm{ef}}(2.8)$ & $87.9^{\mathrm{ef}}(2.6)$ \\
\hline Excite-exp & P-10s & $4.2^{\mathrm{fg}}(0.01)$ & $22.5^{\mathrm{cd}}(1.5)$ & $86.7^{\mathrm{ef}(1.1)}$ & $91.3^{\mathrm{ef}}(0.8)$ \\
\hline Excite-exp & $\mathrm{P}-20 \mathrm{~s}$ & $4.3^{\mathrm{g}}(0.1)$ & $23.3^{\text {cde }}(1.4)$ & $87.6^{\mathrm{ef}}(1.3)$ & $92.1^{\mathrm{ef}}(1.4)$ \\
\hline Excite-exp & U-10s & $4.2^{\mathrm{efg}}(0.1)$ & $23.4^{\mathrm{de}}(2.3)$ & $84.3^{\operatorname{def}}(4.6)$ & $89.0^{\mathrm{ef}}(4.2)$ \\
\hline Excite-exp & $\mathrm{U}-20 \mathrm{~s}$ & $4.2^{\mathrm{fg}}(0.1)$ & $24.8^{\mathrm{e}}(0.8)$ & $87.3^{\mathrm{ef}}(1.9)$ & $92.0^{\mathrm{ef}}(2.0)$ \\
\hline Excite-exp & P-10s-5mm & $3.9^{\mathrm{bc}}(0.2)$ & $21.9^{\mathrm{cd}}(1.4)$ & $82.8^{\operatorname{def}}(1.5)$ & $88.7^{\mathrm{ef}}(1.3)$ \\
\hline Excite-exp & P-20s-5mm & $4.1^{\text {bcdef }}(0.2)$ & $23.2^{\text {cde }}(1.2)$ & $82.8^{\operatorname{def}}(0.2)$ & $88.8^{\mathrm{ef}}(0.8)$ \\
\hline Excite-exp & U-10s-5mm & $4.1^{\operatorname{defg}}(0.1)$ & $23.2^{\text {cde }}(1.6)$ & $80.5^{\mathrm{cde}}(0.1)$ & $85.9^{\text {bcdef }}(0.2)$ \\
\hline Excite-exp & U-20s-5mm & $4.2^{\mathrm{fg}}(0.1)$ & $23.3^{\text {cde }}(1.5)$ & $82.3^{\mathrm{def}}(0.6)$ & $86.9^{\mathrm{def}}(0.3)$ \\
\hline
\end{tabular}

b) Heliobond and Heliobond - experimental:

\begin{tabular}{|c|c|c|c|c|c|}
\hline Adhesive & Exposure & $\mathrm{E}$ & $\mathrm{HV}$ & DC-Height & DC-Area \\
\hline Heliobond & P-10s & $3.5^{\mathrm{bc}}(0.2)$ & $17.5^{\mathrm{b}}(2.8)$ & $66.3^{\mathrm{ab}}(1.7)$ & $71.5^{\mathrm{abc}}(1.9)$ \\
\hline Heliobond & $\mathrm{P}-20 \mathrm{~s}$ & $3.7^{\mathrm{efg}}(0.1)$ & $19.4^{\mathrm{efg}}(2.3)$ & $67.3^{\mathrm{ab}}(2.0)$ & $72.4^{\mathrm{abc}}(2.3)$ \\
\hline Heliobond & B-10s & $3.4^{\mathrm{b}}(0.3)$ & $17.8^{\mathrm{bcd}}(1.7)$ & $67.7^{\mathrm{ab}}(1.1)$ & $72.7^{\mathrm{abc}}(0.4)$ \\
\hline Heliobond & B- $20 \mathrm{~s}$ & $3.7^{\mathrm{efg}}(0.2)$ & $20.1^{\mathrm{fgh}}(0.8)$ & $68.7^{\mathrm{b}}(1.0)$ & $74.2^{\mathrm{c}}(0.9)$ \\
\hline Heliobond & U-10s & $3.7^{\mathrm{def}}(0.1)$ & $19.8^{\mathrm{fgh}}(1.8)$ & $68.2^{\mathrm{ab}}(1.1)$ & $72.6^{\mathrm{abc}}(1.4)$ \\
\hline Heliobond & $\mathrm{U}-20 \mathrm{~s}$ & $3.9^{\mathrm{h}}(0.1)$ & $21.0^{\mathrm{h}}(0.6)$ & $68.5^{\mathrm{ab}}(1.3)$ & $73.1^{\mathrm{bc}}(1.5)$ \\
\hline Heliobond & P-10s-5mm & $3.4^{\mathrm{b}}(0.1)$ & $18.7^{\text {bcdef }}(1.4)$ & $64.6^{\mathrm{ab}}(0.7)$ & $70.1^{\mathrm{abc}}(1.3)$ \\
\hline Heliobond & P-20s-5mm & $3.5^{\mathrm{bc}}(0.2)$ & $19.5^{\mathrm{efg}}(2.5)$ & $67.2^{\mathrm{ab}}(1.1)$ & $71.9^{\mathrm{abc}}(0.7)$ \\
\hline Heliobond & B10s-5mm & $3.1^{\mathrm{a}}(0.3)$ & $13.9^{\mathrm{a}}(2.5)$ & $66.3^{\mathrm{ab}}(1.4)$ & $71.0^{\mathrm{abc}}(1.6)$ \\
\hline Heliobond & B20s-5mm & $3.5^{\mathrm{bc}}(0.3)$ & $19.0^{\operatorname{cdef}}(1.2)$ & $68.1^{\mathrm{ab}}(2.2)$ & $72.7^{\mathrm{abc}}(2.3)$ \\
\hline Heliobond & U10s-5mm & $3.6^{\text {cde }}(0.2)$ & $18.3^{\text {bcde }}(1.4)$ & $66.5^{\mathrm{ab}}(0.8)$ & $71.0^{\mathrm{abc}}(0.5)$ \\
\hline Heliobond & U20s-5mm & $3.8^{\mathrm{fg}}(0.1)$ & $20.7^{\mathrm{gh}}(2.2)$ & $67.8^{\mathrm{ab}}(0.6)$ & $72.4^{\mathrm{abc}}(0.4)$ \\
\hline Heliobond-exp & P-10s & $3.7^{\mathrm{fg}}(0.1)$ & $19.9^{\mathrm{fgh}}(1.4)$ & $67.3^{\mathrm{ab}}(2.0)$ & $70.4^{\mathrm{abc}}(2.3)$ \\
\hline Heliobond-exp & $\mathrm{P}-20 \mathrm{~s}$ & $3.5^{\mathrm{cd}}(0.1)$ & $20.4^{\mathrm{gh}}(3.0)$ & $66.0^{\mathrm{ab}}(2.4)$ & $70.2^{\mathrm{abc}}(2.3)$ \\
\hline Heliobond-exp & U-10s & $3.5^{\mathrm{bc}}(0.2)$ & $17.7^{\mathrm{bc}}(1.6)$ & $64.3^{\mathrm{a}}(2.7)$ & $68.7^{\mathrm{a}}(2.7)$ \\
\hline Heliobond-exp & $\mathrm{U}-20 \mathrm{~s}$ & $3.6^{\mathrm{cd}}(0.2)$ & $20.3^{\mathrm{gh}}(2.8)$ & $66.5^{\mathrm{ab}}(2.9)$ & $70.9^{\mathrm{abc}}(2.2)$ \\
\hline Heliobond-exp & P-10s-5mm & $3.7^{\mathrm{fg}}(0.1)$ & $19.9^{\text {fgh }}(1.1)$ & $66.1^{\mathrm{ab}}(1.9)$ & $69.6^{\mathrm{ab}}(1.8)$ \\
\hline Heliobond-exp & P-20s-5mm & $3.8^{\mathrm{gh}}(0.1)$ & $20.4^{\mathrm{gh}}(1.1)$ & $65.1^{\mathrm{ab}}(1.5)$ & $69.1^{\mathrm{ab}}(1.6)$ \\
\hline Heliobond-exp & U-10s-5mm & $3.7^{\mathrm{def}}(0.2)$ & $19.2^{\operatorname{defg}}(2.4)$ & $65.2^{\mathrm{ab}}(0.7)$ & $69.2^{\mathrm{ab}}(2.4)$ \\
\hline Heliobond-exp & $\mathrm{U}-20 \mathrm{~s}-5 \mathrm{~mm}$ & $3.8^{\mathrm{fgh}}(0.1)$ & $20.4^{\mathrm{gh}}(1.4)$ & $65.4^{\mathrm{ab}}(3.1)$ & $69.7^{\mathrm{ab}}(3.0)$ \\
\hline
\end{tabular}


sives. Values for the experimental materials after polymerization with the regular LED curing unit Bluephase are missing in the table, since this unit was not able to cure Lucirin TPO-containing systems. To determine the influence of replacing CQ with Lucirin TPO in two systems with different chemical compositions, a multivariate statistical analysis was performed separately for each system.

\section{Multivariate statistical analysis results}

1. Excite and Excite-experimental

In the multivariate ANOVA test, the effects of the four main parameters - initiator (CQ and Lucirin TPO), curing unit (Prototype, UltraLume 5, BluePhase), polymerization time (10 seconds and 20 seconds), and distance between curing unit and sample $(0 \mathrm{~mm}$ and $5 \mathrm{~mm}$ ), as well as their interaction products were analyzed. The degree of cure - evaluated from the peak height and peak area, and the mechanical properties (modulus of elasticity and Vickers hardness) were selected as dependent variables. The significance values of these four main effects, as well as of their interaction products, with the exception of "Curing unit * Polymerization time * Initiator", were less than 0.05 - indicating that they all contributed to the model.

Table 3 presents the results of the four tested hypotheses. A (-) sign in the table indicates a reduction, while a $(+)$ sign indicates an increase of the measured characteristic's mean around the marked amount.

Hypothesis 1: Using Lucirin TPO as initiator caused a slight improvement in mechanical properties, but did not modify the degree of cure when compared to the material containing CQ.

Hypothesis 2: The contrast estimates in the multivariate analysis showed that, on average, BluePhase caused a decrease in the degree of cure ( -14.5 for DC-Height and -13.5 for DC-Area), but the mechanical properties measured at 24 hours after photoinitiation did not change when compared to the prototype. As for the comparison between UltraLume 5 and the prototype (Low Power Mode), differences for all the measured properties were not significant.

Hypothesis 3: An increase in polymerization time from 10 seconds to 20 seconds caused an increase in all the measured characteristics.

Hypothesis 4: A 5-mm increase in distance between curing unit and sample surface caused a significant decrease in all the measured characteristics.

2. Heliobond and Heliobond-experimental

The effects of the four main parameters - initiator, curing unit, polymerization time, and distance, as

Table 3 Multivariate test: $(-)$ means a reduction while $(+)$ an increase of the measured characteristic's mean around the marked amount

Excite-group:

\begin{tabular}{|c|c|c|c|c|}
\hline Hypothesis & HV & $\mathrm{E}$ & DC-Height & DC-Area \\
\hline Lucirin-TPO against CQ & 1.699 & .212 & Not sign. & Not sign. \\
\hline Bluephase against Prototype & Not sign. & Not sign. & -14.528 & -13.519 \\
\hline Ultralume against Prototype & Not sign. & Not sign. & Not sign. & Not sign. \\
\hline 20 s against $10 \mathrm{~s}$ & .772 & .183 & 2.480 & 2.247 \\
\hline $5 \mathrm{~mm}$ against $0 \mathrm{~mm}$ & -1.814 & -.141 & -4.134 & -4.733 \\
\hline
\end{tabular}

Heliobond-group:

\begin{tabular}{lcccc}
\hline \multicolumn{1}{c}{ Hypothesis } & HV & E & DC-Height & DC-Area \\
\hline Lucirin-TPO against CQ & Not sign. & Not sign. & -1.197 & -2.092 \\
Bluephase against Prototype & -2.506 & -.226 & Not sign. & Not sign. \\
Ultralume against Prototype & Not sign. & Not sign. & Not sign. & Not sign. \\
20s against 10s & 2.537 & .224 & .995 & 1.319 \\
$5 \mathrm{~mm}$ against $0 \mathrm{~mm}$ & -1.290 & -.064 & Not sign. & Not sign. \\
\hline
\end{tabular}


well as their interaction products were similar to those of Excite group.

Hypothesis 1: The initiator Lucirin TPO slightly reduced the degree of cure without changing the mechanical properties when compared to $\mathrm{CQ}$.

Hypothesis 2: Similarly, the contrast estimates showed that, on average, BluePhase decreased the degree of cure ( -2.5 for DC-Height and -0.2 for DC-Area), while the mechanical properties did not change when compared to the prototype. As for the comparison between UltraLume 5 and the prototype (Low Power Mode), differences for all the measured properties were also not significant.

Hypothesis 3: An increase in polymerization time from 10 seconds to 20 seconds also caused an increase in all the measured characteristics.

Hypothesis 4: A 5-mm increase in distance between curing unit and sample surface caused a slow, but still significant, decrease of the mechanical properties, without changing the degree of cure.

Further, Pearson's correlation analysis of the measured properties for all the four tested adhesives showed that Vickers hardness had a significantly high correlation with the modulus of elasticity (0.6). Moreover, the correlation of mechanical properties with the degree of cure was significant (0.4), whereas the correlation between the two methods to determine the degree of cure was very high (0.9).

\section{DISCUSSION}

With the continuous development of adhesive systems and a relentless attempt to simplify and shorten the bonding procedure, more complex compounds emerged as a result. In particular, selfetching enamel-dentin adhesives - systems with a very low $\mathrm{pH}$ and which entail an acid-base reaction between the acidic monomers and the amine coinitiators of the initiator system - have been unfavorably and unflatteringly charged with diminishing the efficiency of the amine radicals and consequently impeding the polymerization process ${ }^{9-11)}$. On this ground, the search for alternatives to $\mathrm{CQ}$ and amines in adhesive systems is justified and legitimate.

The first hypothesis tested in this study was upheld by the multiple-way ANOVA performed on the experimental data. Comparing the experimental materials containing Lucirin TPO as initiator with their commercial counterparts containing CQ, low differences were found. In the Excite group, Lucirin TPO as initiator caused a slight improvement in the mechanical properties but did not modify the degree of cure when compared to the material containing CQ. For the Heliobond group, there was a slight reduction in the degree of cure when Lucirin TPO was used as initiator, but the measured mechanical properties barely differed. Upon applying one-way
ANOVA, it was found that when curing with the same curing unit and under the same curing conditions, the differences in degree of cure between Heliobond with Lucirin TPO and Heliobond with CQ were not significant.

The physical properties of cured adhesives are affected by the generation of primary radicals during the initial stage of polymerization. In the context of this study, the two initiators examined differed significantly in their initiation mechanisms for radical polymerization. With Lucirin TPO, the photochemical process leads to the cleavage of carbon-phosphorus bond, consequently forming two polymerization initiating radicals: acyl which is less efficient, and phosphonyl which is more reactive ${ }^{17,18)}$. With CQamine systems, only one active radical is expected, since only the $\boldsymbol{\alpha}$-radicals derived from the amine $\mathrm{H}$ transfer are considered effective for polymerization initiation $^{3)}$. In terms of polymerization efficiency, studies on methyl methacrylate monomer containing different initiators reported that Lucirin TPO gave a higher efficiency compared to $\mathrm{CQ}$, phenylpropanedione (PPD), and bisacylphosphine oxide (Irgacure 819), when the material was cured with a halogen light curing unit ${ }^{19)}$. When testing was performed with composites - made using different initiators based on Bis-GMA, UDMA, and D3MA as matrix (25 wt\%) and barium silicate glass and ytterbium fluoride as filler (75 wt\%) - cured using a halogen light curing unit, acylphosphine oxide as initiator did not increase the flexural strength and modulus of elasticity in comparison to the same composite containing $\mathrm{CQ}$ or $\mathrm{PPD}^{20)}$.

The second hypothesis in this study was also accepted. First, it must be clarified that the curing of experimental materials by the regular LED unit BluePhase was disregarded, due to the latter's incompatibility with the absorption spectrum of Lucirin $\mathrm{TPO}^{16)}$. Based on the results of the commercial adhesives, multivariate analysis showed that the prototype curing unit with dual-wavelength emission LED performed generally better than BluePhase. In particular, the effect seemed to be more apparent for Excite than for Heliobond. It is noteworthy that these two materials not only differed in their chemical compositions, but also in the filler amount, which would then lead to noticeable changes in both viscosity and molecular mobility.

Discrepancies in the efficiency of curing units became more evident with increased distance between the curing unit and sample surface. The turbo light guide of BluePhase curing unit showed a more rapid decrease in light intensity with distance than the standard light guide of the prototype. Whereas the characteristics of the adhesives were not significantly different when the curing unit was applied directly on the sample surface, curing from a 
distance of $5 \mathrm{~mm}$ with BluePhase evidently decreased the degree of cure and mechanical properties of the adhesives. Then, between UltraLume 5 and the prototype, statistical comparison indicated no significant differences in the measured characteristics, although the total light output of the former was higher. For UltraLume 5, the LED light sources were placed directly in the curing footprint, thus making the light guide superfluous and consequently reduced the decrease of light intensity with distance. In the comparison of UltraLume 5 versus the prototype, it must also be mentioned that the prototype was applied in Low Power Mode indicated for curing adhesives. The High Power Mode of the same unit was able to provide an irradiance of $1100 \mathrm{~mW} / \mathrm{cm}^{2}$, whereas the irradiance of UltraLume 5 was not adjustable.

Regarding the efficiency of curing materials containing Lucirin TPO, the first peak $(405 \mathrm{~nm})$ of the prototype was much higher than the first peak of UltraLume 5. As for the effect of distance, there were no significant differences in the measured characteristics of the experimental materials after curing with these two units at direct contact on the sample surface or from a distance of $5 \mathrm{~mm}$. Therefore, it was not necessary to increase the output power at this wavelength. At this juncture, it must be mentioned that the radiation emitted by both dual-wavelength curing units at the lower wavelength (first peak $c a .400 \mathrm{~nm}$ ) indeed produced an inferior output compared to the radiation emitted at the absorption wavelength of $\mathrm{CQ}$ (second peak at $470 \mathrm{~nm}$ ). The experimental materials would not be cured by the solo existence of the second peak. Notwithstanding, no differences were found in the properties of the adhesives when CQ was replaced by Lucirin TPO. The reason therefore lay in the different extinction coefficients of the two initiators, whereby that of Lucirin TPO at the maximum absorption wavelength $(390 \mathrm{~nm})$ is considerably larger than the extinction coefficient of CQ at $470 \mathrm{~nm}^{15}$.

The third hypothesis tested in this study was also proven valid. An increase of exposure time from 10 seconds to 20 seconds caused an improvement in the measured characteristics. However, this effect was lower than the effect of curing with different curing units.

Similarly, the fourth hypothesis was upheld by the experimental data. The distance between curing unit and sample surface indeed influenced the measured characteristics of the adhesives. However, it must be distinguished between the effect of the turbo light guide of BluePhase, which consistently caused a decrease in adhesives properties, versus the standard light guide of the prototype and UltraLume 5, which showed less or no significant decrease in the measured properties with distance.

Correlation analysis results of the measured characteristics for all the tested materials showed that mechanical characteristics correlated significantly in two aspects: among themselves (i.e., modulus of elasticity with Vickers hardness) and with the degree of cure. On the two methods to determine the degree of cure, peak height versus peak area, a very good correlation was found (0.9). This very good correlation could therefore lead to the assumption that the method to determine the degree of cure was less important. Nonetheless, it is noteworthy that the values for the degree of cure determined by considering the peak area were higher than those determined by analyzing the peak height. Therefore, one ought to exercise care and discretion when comparing the results of different tests.

\section{CONCLUSIONS}

Experimental data showed that the CQ-amine system could be completely replaced by Lucirin TPO when dual-wavelength LED units were used for photoactivation. Increasing the polymerization time and decreasing the distance between curing unit and sample surface resulted in superior properties of the adhesives. Further, the dual-wavelength LED prototype tested in this study proved to be able to adequately cure all the tested dental adhesives with different initiator systems.

\section{ACKNOWLEDGEMENTS}

The authors specially thank Mr. Wolfgang Plank for his assistance in the measurement of the spectral distributions of the tested curing units as well as Dr. Thomas Völkel for his kind support.

\section{REFERENCES}

1) Jakubiak J, Allonas X, Fouassier JP, et al. Camphorquinone-amines photoinitiating systems for the initiation of free radical polymerization. Polymer 2003; 44: 5219-5226.

2) Stansbury JW. Curing dental resins and composites by photopolymerization. J Esthet Dent 2000; 12: 300-308.

3) Teshima W, Nomura Y, Tanaka N, Urabe H, Okazaki M, Nahara Y. ESR study of camphorquinone/amine photoinitiator systems using blue light-emitting diodes. Biomaterials 2003; 24: 2097-2103.

4) Janda R, Roulet JF, Kaminsky M, Steffin G, Latta M. Color stability of resin matrix restorative materials as a function of the method of light activation. Eur J Oral Sci 2004; 112: 280-285.

5) Asmussen E. Clinical relevance of physical, chemical, and bonding properties of composite resins. Oper Dent 1985; 10: 61-73.

6) Williams D (ed.). Concise encyclopedia of medical \& dental materials, Pergamon Press, Oxford, UK, 
1990, pp.8-21.

7) Weisburger EK, Russfield AB, Homburger F, et al. Testing of twenty-one environmental aromatic amines or derivatives for long-term toxicity or carcinogenicity. J Environ Pathol Toxicol 1978; 2: 325-356.

8) Nomura Y, Teshima W, Kawahara T, et al. Genotoxicity of dental resin polymerization initiators in vitro. J Mater Sci Mater Med 2006; 17: 29-32.

9) Cheong C, King NM, Pashley DH, Ferrari M, Toledano M, Tay FR. Incompatibility of self-etch adhesives with chemical/dual-cured composites: two-step vs one-step systems. Oper Dent 2003; 28: 747-755.

10) Sanares AM, Itthagarun A, King NM, Tay FR, Pashley DH. Adverse surface interaction between one-bottle light-cured adhesives and chemical-cured composites. Dent Mater 2001; 17: 542-556.

11) Moszner N, Salz U. Recent developments of new components for dental adhesives and composites. Macromolecular Materials and Engineering 2007; 292: 245-271.

12) Ahn KD, Han DK, Lee SH, Lee CW. New aromatic tert-amines for application as photoinitiator components in photocurable dental materials. Macromol Chem Phys 2003; 204: 1628-1635.

13) Angiolini L, Caretti D, Rossetti S, Salatelli E, Scoponi M. Radical polymeric photoinitiators bearing side-chain camphorquinone moieties linked to the main chain through a flexible spacer. J Polym
Sci Part A: Polym Chem 2005; 43: 5879-5888.

14) Moszner N, Salz U. Recent developments of new components for dental adhesives and composites. Macromol Mater Eng 2007; 292: 245-271.

15) Neumann MG, Miranda WG, Jr., Schmitt CC, Rueggeberg FA, Correa IC. Molar extinction coefficients and the photon absorption efficiency of dental photoinitiators and light curing units. J Dent 2005; 33: 525-532.

16) BASF Corporation. Lucirin TPO, Technical Information. http://www.basf.com/rawmaterials/ pdfs/LUC-TPO.pdf. 2001.

17) Kajiwara A, Konishi Y, Morishima Y, Schnabel W, Kuwata K, Kamachi M. Time-resolved electron spin resonance study on radical polymerization with $(2,4$, 6 -trimethylbenzoyl) diphenylphosphine oxide. Direct estimation of rate constants for addition-reactions of diphenylphosphonyl radicals to vinyl monomers. Macromolecules 1993; 26: 1656-1658.

18) Kolczak U, Rist G, Dietliker K, Wirz J. Reaction mechanism of monoacyl- and bisacylphosphine oxide photoinitiators studied by ${ }^{31} \mathrm{P}-,{ }^{13} \mathrm{C}-$, and ${ }^{1} \mathrm{H}-\mathrm{CIDNP}$ and ESR. J Am Chem Soc 1996; 118: 6477-6489.

19) Neumann MG, Schmitt CC, Ferreira GC, Correa IC. The initiating radical yields and the efficiency of polymerization for various dental photoinitiators excited by different light curing units. Dent Mater 2006; 22: 576-584.

20) Burtscher P, Rheinberger V. Efficiency of various light initiators after curing with different lightcuring units. J Dent Res 2003; Abstr No. 0042. 